\title{
Game Sejarah Terbentuknya Kota Samarinda Menggunakan Role Playing Game (RPG) Maker VX Ace
}

\author{
Septya Maharani ${ }^{1}$, Heliza Rahmania Hatta $^{2}$, Firdha Ayu Selvyani ${ }^{3}$ \\ ${ }_{1,2,3}$ Program Studi Ilmu Komputer, FMIPA, Universitas Mulawarman \\ 1,2,3 Jalan Barong Tongkok No. 27 Samarinda, Kalimantan Timur \\ Email korespondensi : heliza_rahmania@yahoo.com
}

Dikirim 02 Februari 2016, Diperbaiki 22 Maret 2016, Diterima 31 Maret 2016

\begin{abstract}
Abstrak - Cerita dan sejarah dari terbentuknya sebuah daerah ataupun sebuah tempat memiliki nilai pembentuk akan suatu pola kehidupan serta budaya masyarakat. Informasi sejarah banyak terdapat di buku dan artikel tetapi kebanyakan informasi tersebut dominan berisi tulisan sehingga membuat minat orang untuk membaca kurang sehingga pada era ini sangat sulit untuk menemukan orang terutama anak-anak yang mengetahui tentang sejarah terbentuknya sebuah daerah ataupun tempat. Game merupakan salah satu media yang selain menghibur, juga dapat digunakan sebagai media informasi dan pembangkit motivasi yang efektif. Atas dasar inilah dibangun sebuah game yang menceritakan terbentuknya salah satu kota di Indonesia yaitu Samarinda dalam game yang berjudul Sejarah Terbentuknya Kota Samarinda. Game Sejarah Kota Samarinda merupakan game berjenis Role Playing Game (RPG) yaitu game yang hampir keseluruhan permainannya didasarkan pada cerita. Game ini dibangun dengan menggunakan sebuah RPG Editor Engine atau mesin pengedit RPG yaitu RPG Maker VX Ace. Storyline game dibangun berdasarkan alur cerita dari sejarah terbentuknya kota Samarinda. Game ini didukung dengan berbagai fitur didalamnya yang terdiri dari berbagai jenis misi dan semtuhan graphic 2d. Setelah game Sejarah Terbentuknya Kota Samarinda dibangun, maka dilakukanlah pengujian untuk mengetahui apakah game berjalan dengan baik sehingga game ini dapat dijadikan sebagai media informasi yang dapat membuat pemain tertarik mempelajari sejarah terbentuknya kota Samarinda. Dari hasil pengujian secara fungsionalitas game ini memenuhi harapan dari peneliti untuk mengemas pendidikan dalam bentuk game.
\end{abstract}

Kata Kunci - Game, Sejarah, Role Playing Game, RPG, Samarinda

Abstract - Story and history of the formation of a region or a place has to be a pattern forming values and cultural life of the community. The historical information is widely available in books and articles, but most of the information is predominantly contained the writings that make people's interest in reading is less so in this era is very difficult to find people, especially children who know about the history of the formation of a region or a place. Game is a media that entertaining and can be used as an informative and motivational media. Based on the problem stated above, a game that tells the story about one of Indonesian city, Samarinda. The History Of Samarinda game is a Role Playing Game (RPG) where the gameplay is mostly based on the storyline. This game is built using an RPG Editor engine that is RPG Maker VX Ace. This game has many feature, like diffent mission and for graphic feature this game use unique 2D style, like The storyline of the game is based on the history city of Samarinda. After the History of Samarinda game is built, a test is performed in order to know whether of this game is successfully running and can be used as an informative media that appeal people to learn the history of Samarinda. In function side this game can bring a good and new thing for education method.

Keywords - Game, History, Role Playing Game, RPG, Samarinda

\section{PENDAHULUAN}

Samarinda adalah salah satu kota sekaligus merupakan ibu kota dari provinsi Kalimantan Timur. Namun, pada era ini sudah sangat sulit bagi masyarakat mengetahui tentang sejarah awal terbentuknya kota Samarinda. Sedangkan telah banyak buku dan artikel yang memberikan informasi bagaimana sejarah kota Samarinda ini dapat terbentuk. Tetapi kebanyakan informasi dari buku dan artikel tersebut dominan berisi tulisan sehingga membuat minat masyarakat untuk membaca kurang. Namun, akan berbeda jika informasi yang diberikan berupa visual (gambar) serta sound (suara) yang mendukung. Salah satunya adalah dengan menggunakan media game. Media permainan atau game diciptakan sebagai sarana hiburan, tetapi akan lebih baik jika game diciptakan sebagai sarana belajar 
supaya anak-anak dapat lebih kreatif dalam berfikir [1].

Role Playing Game (RPG) adalah salah satu jenis game pilihan karena memasukkan unsur-unsur penceritaan yang kompleks serta seni peran yang membuat seseorang merasa seperti menjadi tokoh yang diperankannya dalam game tersebut. RPG Maker VX Ace adalah satu dari sekian banyak program yang akan membantu penulis dalam membangun sebuah game RPG buatan. Program ini adalah program yang cukup baik dalam perannya sebagai sebuah RPG Editor Engine atau mesin pengedit RPG, dimana RPG buatan dapat menjadi sebuah program game dua dimensi mandiri yang dapat dimainkan langsung tanpa bantuan program lain [2].

Dalam mengenalkan sejarah, game yang dikembangkan ditujukan untuk usia anak-anak dengan menampilkan konten yang sesuai dan menarik bagi anak-anak. Game dapat dimainkan di desktop secara offline dan merupakan game singleplayer yang dimainkan oleh satu orang saja. Dengan adanya game tersebut, diharapkan anak-anak dapat memainkan game dengan konten yang sesuai.

\section{METODOLOGI PENELITIAN}

Dalam melakukan penelitian untuk memperoleh data menggunakan metode dokumentasi yaitu pengumpulan dokumen-dokumen yang berkaitan dengan penelitian. Adapun dalam penelitian ini metode dokumentasi digunakan untuk memperoleh data tentang sejarah kota samarinda, tokoh-tokoh penting dalam sejarah, dan mengenai game $R P G$.

\section{A. Tahap Pengembangan Game}

1. Analisis Kebutuhan

Tahap ini merupakan tahap menganalisis halhal yang dibutuhkan dalam pelaksanaan proyek pembuatan game yang dibagi menjadi kebutuhan fungsional dan kebutuhan non-fungsional.

\section{Perancangan Game}

Tahap ini membahas perancangan game, meliputi jalan cerita (storyline), tata cara permainan (gameplay), karakter pemain utama, peta (maps), event dan suara (sound).

Pada Gambar 1 dijelaskan bahwa game "Sejarah Terbentuknya Kota Samarinda" ini dibagi menjadi empat sesi yang disesuaikan dengan storyline secara keseluruhan. Pada sesi pertama misinya adalah mencari jalan untuk menuju ke Sekolah, sesi kedua misinya adalah mengalahkan musuh, sesi ketiga misinya adalah berlayar menuju ke Kerajaan Ing Martadipura, dan sesi terakhir misinya adalah mengumpulkan kayu dan menjawab soal di akhir game.

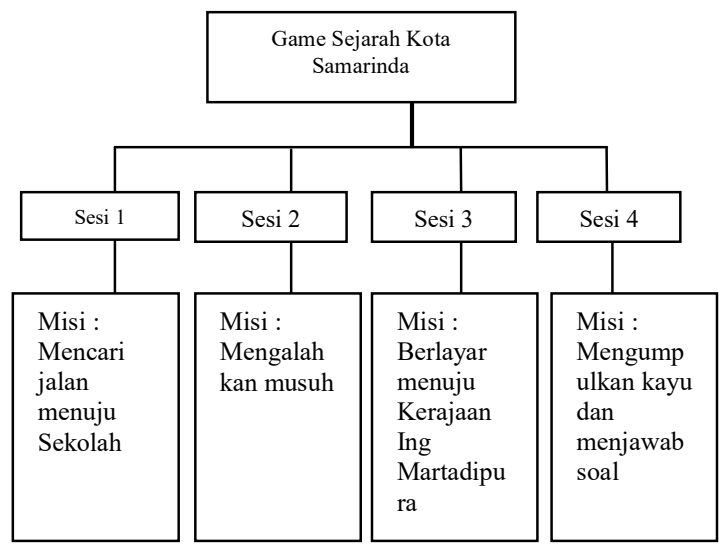

Gambar 1. Rancangan Game "Sejarah Terbentuknya Kota Samarinda"

3. Implementasi

Tahap ini meliputi implementasi hasil desain sistem melalui pengkodean. Produk berupa aplikasi game.

4. Pengujian

Tahap ini merupakan ujicoba dari game yang telah dibuat, yaitu dengan menjalankan permainan dan mengevaluasi apakah implementasi sistem sudah sesuai dengan tujuan yang ingin dicapai.

B. Analisis Kebutuhan Non-Fungsional

1. Analisis Kebutuhan Perangkat Keras

Perangkat keras yang dibutuhkan untuk membangun game ini adalah sebagai berikut.

a. Processor Intel Core i3 2,10 GHz

b. Memori (RAM) DDR3 2 GB

c. Harddisk dengan kapasitas 512 GB

Sedangkan spesifikasi minimum perangkat keras yang dibutuhkan untuk menjalankan game ini adalah sebagai berikut.

a. Processor Intel Core 2 Duo

b. Kapasitas Harddisk minimal 4 GB

c. RAM minimal $1 \mathrm{~GB}$

2. Analisis Kebutuhan Perangkat Lunak

Perangkat lunak yang digunakan untuk membangun game ini adalah sebagai berikut.

a. RPG Maker VX Ace

b. Adobe Photoshop X6 


\section{Analisis Kebutuhan Fungsional}

\section{Use Case Diagram}

Diagram Use Case merupakan konstruksi untuk mendeskripsikan hubungan yang terjadi antara actor dengan aktivitas yang terdapat pada sistem [3]. Berikut use case diagram game RPG "Sejarah Terbentuknya Kota Samarinda".

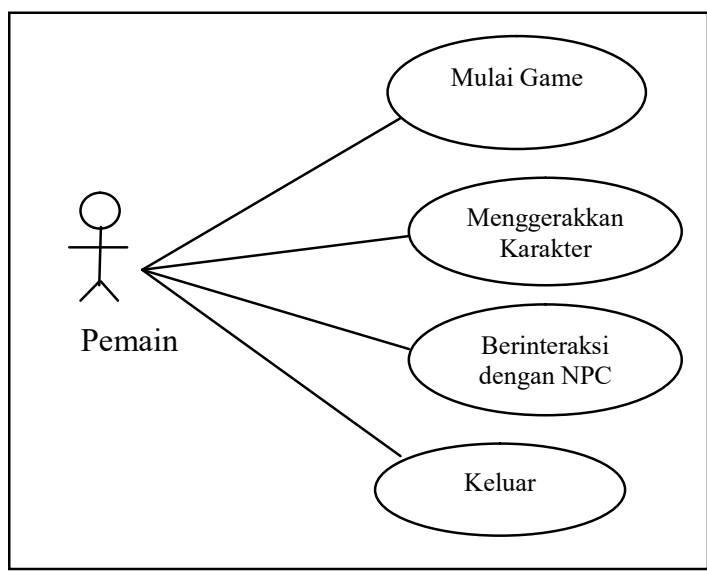

Gambar 2. Use Case Game Sejarah Terbentuknya Kota Samarinda

Pada Gambar 2 dapat dilihat bahwa pemain dapat melakukan beberapa aksi pada game. Dalam menu utama pemain dapat memilih "Mulai Game" untuk masuk ke dalam game dan "Keluar" untuk keluar dari aplikasi game. Pemain juga dapat menggerakkan karakter dalam game dan berinteraksi dengan NPC.

\section{Activity Diagram}

Activity Diagram menggambarkan berbagai alir aktivitas (workflow) dalam sistem yang dirancang, bagaimana masing-masing alir berawal, pilihan (decision) yang mungkin terjadi, dan bagaimana permainan berakhir [3]. Activity Diagram dalam game "Sejarah Terbentuknya Kota Samarinda" ditunjukkan pada Gambar 3. Pada Gambar 3 dijelaskan alur aktifitas yang terjadi saat karakter pemain digerakkan di dalam game. Dalam game RPG pemain mengendalikan seorang karakter untuk dapat menyelesaikan misi-misi yang terdapat di dalam game. Untuk menggerakkan karakter di dalam game, pemain harus menekan tombol arah pada keyboard. Saat pemain menekan tombol arah atas pada keyboard, sistem menggerakkan karakter ke atas. Saat pemain menekan tombol arah kanan pada keyboard, sistem menggerakkan karakter ke kanan. Saat pemain menekan tombol arah bawah pada keyboard, sistem menggerakkan karakter ke bawah. Saat pemain menekan tombol arah kiri pada keyboard, sistem menggerakkan karakter ke kiri.

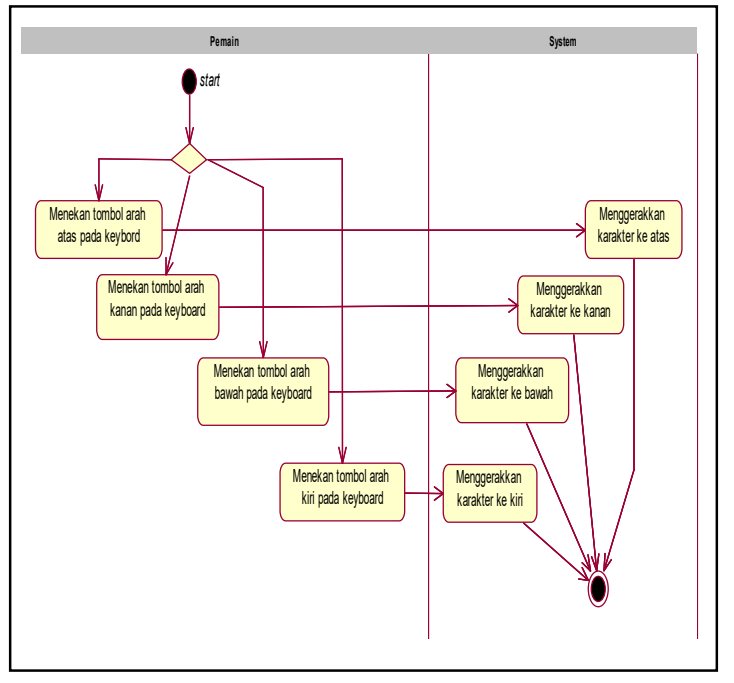

Gambar 3. Activity Diagram Menggerakkan Karakter

\section{HASIL DAN PEMBAHASAN}

\section{A. Alur Cerita (Storyline)}

Storyline atau cerita dari game ini yaitu menceritakan sejarah awal berdirinya kota Samarinda yang bermula dari kedatangan sekelompok suku Bugis Wajo yang dipimpin oleh La Mahong Daeng Mangkona akibat dari kerusuhan di Kerajaan Bone. Rombongan Bugis Wajo datang ke daerah kerajaan Ing Martadipura hingga mereka di izinkan bermukim di daerah Kerajaan Ing Martadipura [4], yang mana keseluruhan storyline tersebut terbagi atas empat sesi.

Sesi pertama berlatar di Rumah Aji, Aji bangun dari tidurnya dan bersiap-siap untuk berangkat ke sekolah. Setelah bersiap-siap, Aji sarapan bersama Ayah dan Ibunya. Lalu Aji pamit ke Ayah dan Ibunya untuk berangkat sekolah. Sesampainya di sekolah, Aji mendapatkan materi dari Bapak Guru yaitu sejarah kota Samarinda.

Sesi kedua berlatar di Kerajaan Ing Martadipura yang berpusat di Kutai Lama yang dipimpin oleh Sultan Pangeran Dipati Modjo Kusumo. La Mohang Daeng Mangkona datang menyembah ke hulu sang Raja agar dapat bermukim di daerah kerajaan dan diterima menjadi rakyat Kutai. Atas hasil musyawarah dewan kerajaan, permintaan La Mohang Daeng Mangkona dikabulkan tetapi dengan perjanjian bahwa orang-orang Bugis Wajo harus membantu segala kepentingan Raja Kutai, terutama di dalam menghadapi musuh. 
Sesi ketiga berlatar di Loa Buah, La Mohang Daeng Mangkona dan pengikutnya diberi daerah Loa Buah di tepi sungai Mahakam. Setelah ditempati, ternyata daerah itu tidak cocok untuk lahan persawahan karena terdiri atas tanah berbukit-bukit. Lalu La Mohang Daeng Mangkona menghadap Sultan Pangeran Dipati Modjo Kusumo agar diberi tanah datar yang cocok sebagai lahan persawahan. Atas kemurahan hati sang raja, permintaan La Mohang Daeng Mangkona dikabulkan dan diberi tempat di daratan rendah di tepi kiri Sungai Mahakam.

Sesi ketiga berlatar di Daratan Rendah di tepi kiri Sungai Mahakam, Disini La Mohang Daeng Mangkona mulai membangun daerah baru dengan bantuan seluruh pengikutnya. Hutan belantara ditebas dan kayu-kayu besar ditebang. Setelah lahan terbuka pohon-pohon kering dibakar sehingga terbukalah daerah persawahan yang luas di tanah datar dan rendah tanpa bukit-bukit. Rumah-rumah didirikan di tepi Sungai Mahakam dan dikerjakan secara gotong royong.

\section{B. Tata Cara Permainan (Gameplay)}

Gameplay menggambarkan bagaimana interaksi yang dapat dilakukan antara pemain dengan game, pola dan aturan permainan serta kaitannya dengan storyline [5]. Game ini bersifat single player dimana hanya satu pemain yang dapat memainkan game ini dalam satu waktu.

Saat memulai permainan, pemain dapat memilih 2 menu utama yang disediakan yaitu menu Mulai Game dan Keluar. Jika pemain memilih menu "Mulai Game", maka prolog akan ditampilkan dan game akan dimulai. Jika memilih menu "Keluar", maka game akan dihentikan dan jendela aplikasi akan ditutup.

Memilih menu "Mulai Game" pada dasarnya akan menyajikan permainan sesuai storyline yang mana berpengaruh terhadap gameplay. Pada sesi pertama storyline, pemain berperan sebagai Aji, seorang murid kelas VI SDN. 034 Samarinda. Misi di sesi pertama ini yaitu mencari jalan untuk menuju ke sekolah dengan mengikuti petunjuk yang diberikan oleh NPC (Non-Player Character) yang ditemui saat perjalanan menuju sekolah. Pada sesi kedua storyline, pemain memerankan karakter La Mohang Daeng Mangkona yang merupakan pimpinan dari rombongan Bugis Wajo. Pemain harus mengalahkan semua musuh sehingga dapat lanjut ke cerita selanjutnya. Pada sesi ketiga storyline, pemain berlayar menuju ke Kerajaan Ing Martadipura. Pada sesi terakhir storyline, pemain harus mengumpulkan kayu dan menjawab soal-soal yang telah ditentukan.

Pemain dapat menjelajahi arena permainan dengan menggerakkan karakter pemain ke arah kanan, kiri, atas dan bawah. Jika pemain berada di tempat yang memicu cerita game, maka cerita game akan ditampilkan dan pemain harus mengikuti alur penyajian cerita tersebut hingga penyajian cerita selesai lalu kemudian permainan dapat dilanjutkan kembali.

\section{Peta (Maps)}

Dalam RPG Maker VX, maps berfungsi sebagai tempat/petunjuk lokasi dari perjalanan karakter dan juga tempat meletakkan berbagai macam event yang terjadi dalam game RPG[6]. Untuk membuat peta dapat dilakukan dengan menekan tombol kanan pada browser peta dalam map toolbar dan kemudian tekan tombol New Maps. Dalam game ini ada 34 maps yang digunakan. Berikut tampilan dari beberapa maps dalam game "Sejarah Terbentuknya Kota Samarinda".

Sesi 1.

Pada sesi pertama terdiri dari 7 maps yang dibuat dengan nama masing-masing sebagai berikut yaitu scene 1 rumah, halaman rumah, kamar, taman, luar sekolah, dalam sekolah, dan ruang kelas seperti ditunjukkan pada Gambar 4.

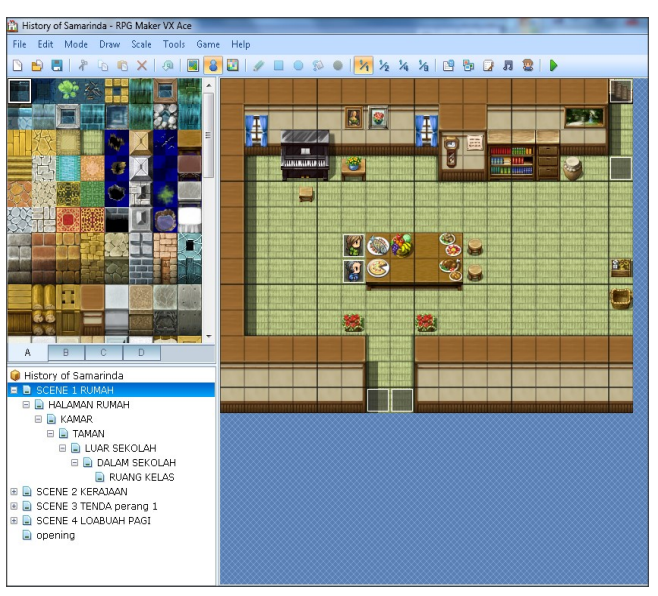

Gambar 4. Tampilan Maps Sesi 1

Sesi 2.

Pada sesi kedua terdiri dari 12 maps yang dibuat dengan nama masing-masing sebagai berikut yaitu scene 2 Kerajaan, maps Kerajaan Kutai, dalam Kerajaan, luar Kerajaan Kutai, Kerajaan Kutai setelah, hutan menuju Loa Buah, hutan Loa Buah, Loa Buah malam, scene tenda perang 1, tenda Pua perang, tenda perang start, 
dan tenda Pua seperti yang ditunjukkan pada Gambar 5.

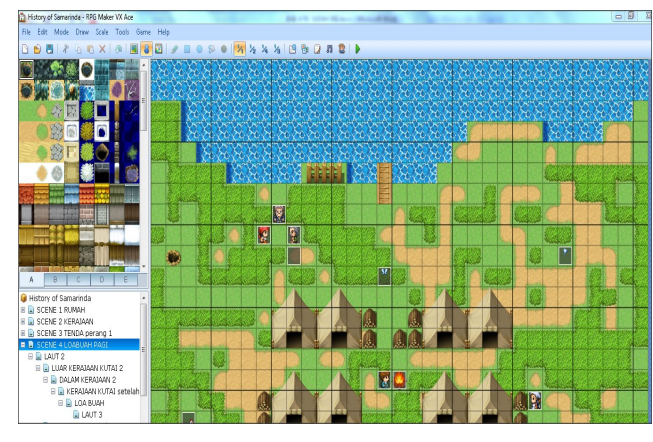

Gambar 5. Tampilan Maps Sesi 2

Sesi 3.

Pada sesi pertama terdiri dari 7 maps yang dibuat dengan nama masing-masing sebagai berikut yaitu scene Loa Buah pagi, laut 2, luar Kerajaan Kutai 2, Dalam Kerajaan 2, Kerajaan Kutai setelah, Loa Buah, dan laut 3 seperti yang ditunjukkan pada Gambar 6 .

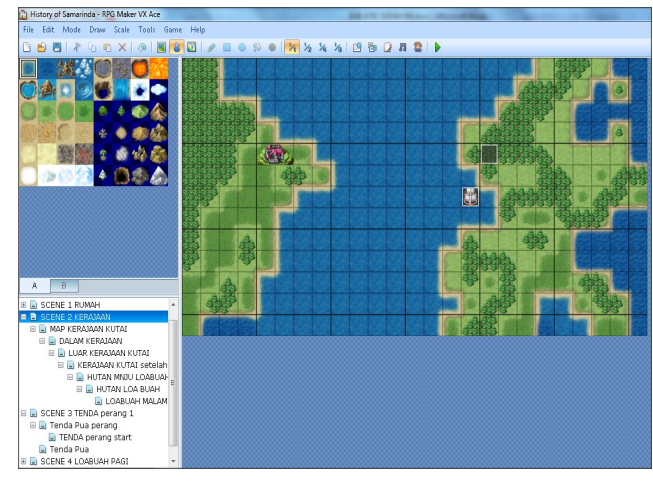

Gambar 6. Tampilan Maps Sesi 3

Sesi 4.

Pada sesi pertama terdiri dari 8 maps yang dibuat dengan nama masing-masing sebagai berikut yaitu scene Loa Buah pagi, laut 2, luar Kerajaan Kutai 2, Dalam Kerajaan 2, Kerajaan Kutai setelah, Loa Buah, laut 3 dan ending seperti yang ditunjukkan pada Gambar 7.

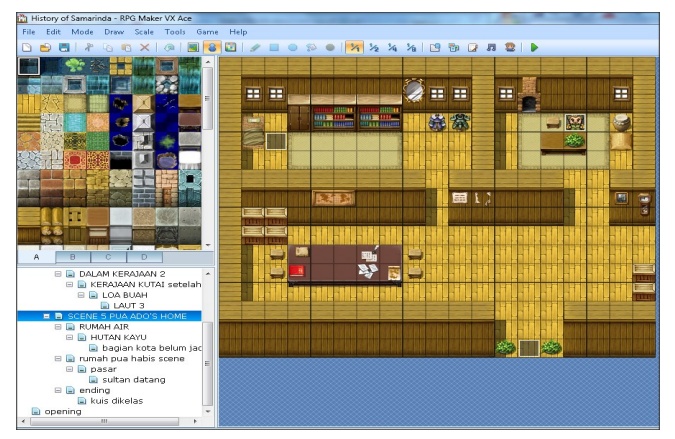

Gambar 7. Tampilan Maps Sesi 4

\section{Karakter Pemain Utama}

Karaker pemain utama dalam game "Sejarah Terbentuknya Kota Samarinda" dapat dilihat pada tabel 4.1 . Tokoh Aji adalah tokoh utama yang mewakili pengguna untuk bermain. Tokoh La Mohang Daeng Mangkona (pendatang yang berasal dari pulau sulawesi) dan Sultan Pengeran Dipati Kusumo merupakan tokoh raja dari kerajaan Ing Martadipura, Pada Tabel 1 dijelaskan karakter pada game.

Tabel. 1 Karakter Pemain

\begin{tabular}{|c|c|c|c|}
\hline No & Nama & Gambar & Keterangan \\
\hline 1 & Aji & & $\begin{array}{c}\text { Anak laki-laki yang } \\
\text { penuh semangat dan } \\
\text { berbakti kepada orang } \\
\text { tuanya }\end{array}$ \\
\hline 2 & $\begin{array}{l}\text { La Mohang } \\
\text { Daeng } \\
\text { Mangkona }\end{array}$ & & $\begin{array}{c}\text { Pemimpin rombongan } \\
\text { dari kerajaan Gowa } \\
\text { yang sangat gigih dan } \\
\text { bijaksana }\end{array}$ \\
\hline 3 & $\begin{array}{l}\text { Sultan } \\
\text { Pangeran } \\
\text { Dipati } \\
\text { Modjo } \\
\text { Kusumo }\end{array}$ & & $\begin{array}{l}\text { Sultan dari Kerajaan } \\
\text { Ing Martadipura yang } \\
\text { sangat murah hati dan } \\
\text { tinggi rasa sosialnya. }\end{array}$ \\
\hline
\end{tabular}

\section{E. Event}

Event sendiri dapat dibagi menjadi beberapa macam seperti event cerita, harta karun, toko atau penginapan, puzzle dan event support [7]. Secara umum, untuk membuat event dalam game RPG Maker VX Ace harus berada di peta pada event layer. Caranya dengan menekan tombol icon Events pada standart toolbar, maka peta akan dibatasi oleh grid atau kotak-kotak di mana tempat untuk meletakan suatu event.

\section{F. Suara (Sound)}

Suara yang digunakan yaitu seperti SE (Sound Effect) contohnya suara bell yang digunakan di awal game, BGS (Background Sound) contohnya suara seperti efek api, hembusan angin, dan BGM (Background Music) merupakan musik pengiring sebagai latar belakang setiap map salah satu contohnya yaitu BGM Town. Sound sendiri disesuaikan dengan map yang sedang dijelajahi [8].

\section{G. Implementasi}

Setelah dilakukan perancangan, maka dilakukan pengimplementasian pada game. Adapun hasil dari pengimplementasian tersebut dapat dilihat dalam gambar-gambar berikut. 


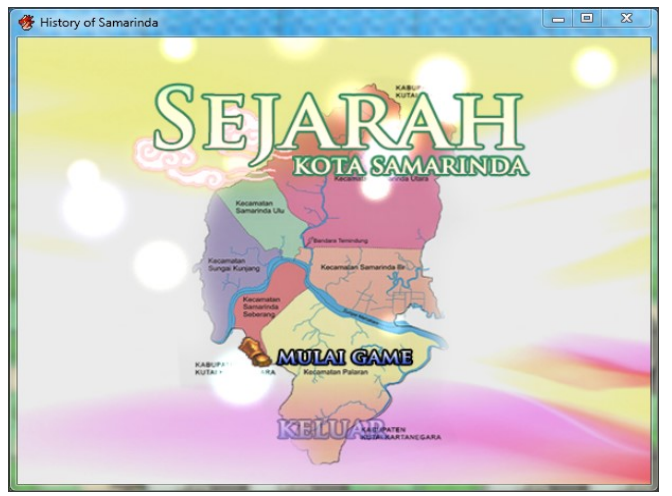

Gambar 8. Tampilan Menu

Pada Gambar 8, pemain dapat memilih untuk memulai game baru atau keluar dari game. Jika pemain memilih menu "Mulai Game" maka game akan dimulai, jika pemain memilih menu "Keluar" maka aplikasi game akan ditutup. Game diawali dengan misi pada sesi pertama storyline ini yaitu mencari jalan untuk menuju ke sekolah.

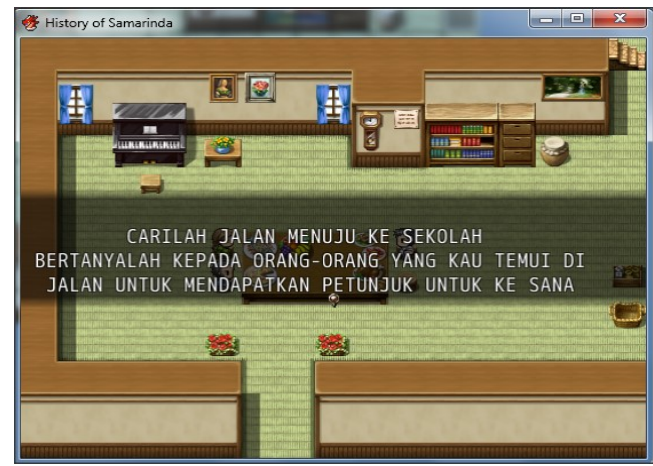

Gambar 9. Tampilan Misi Sesi 1

Pada Gambar 9, pemain harus mencari jalan untuk menuju ke sekolah dengan mengikuti petunjuk yang diberikan oleh NPC (Non-Player Character) yang ditemui saat perjalanan menuju sekolah.

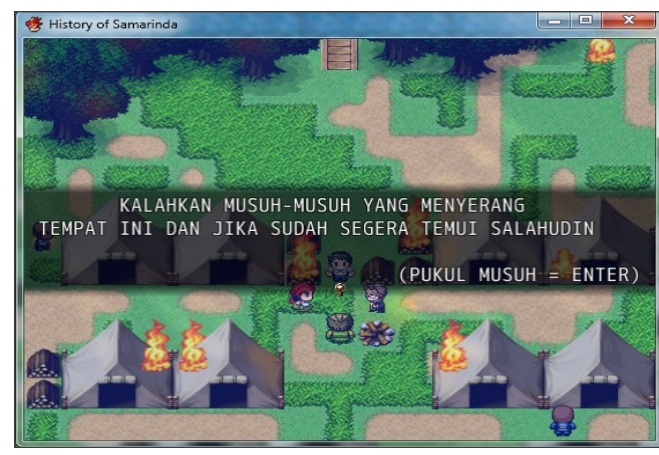

Gambar 10. Tampilan Misi Sesi 2

Pada Gambar 10 merupakan tampilan misi yang ada di sesi kedua storyline, pemain harus mengalahkan semua musuh sehingga dapat lanjut ke cerita selanjutnya.

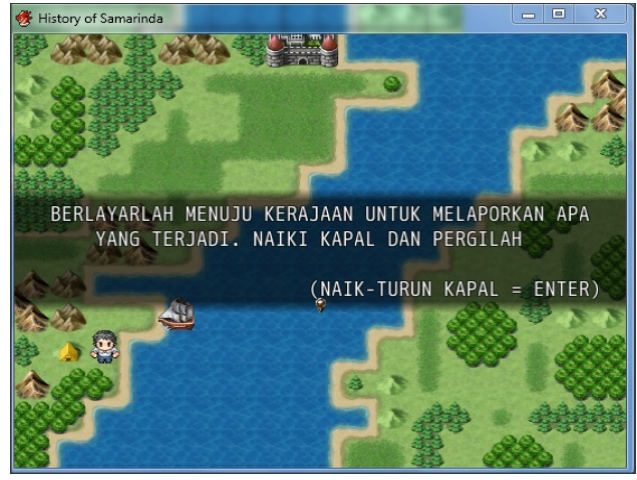

Gambar 11. Tampilan Misi Sesi 3

Pada Gambar 11 merupakan tampilan dari misi yang ada di sesi ketiga storyline. Pemain diperintahkan untuk berlayar menuju ke Kerajaan Ing Martadipura.

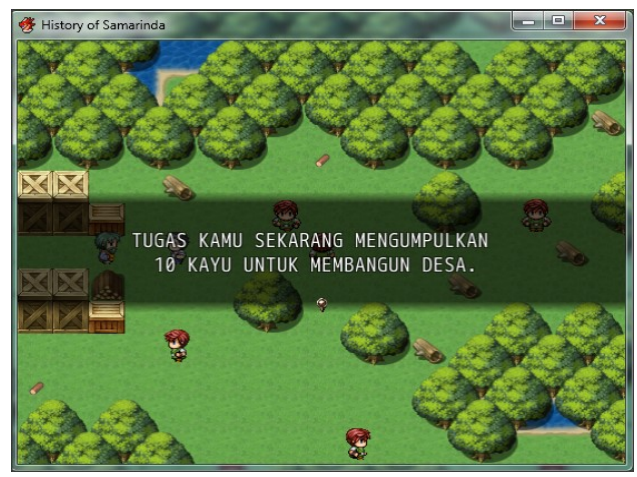

Gambar 12. Tampilan Misi Sesi 4

Pada Gambar 12 merupakan tampilan misi di sesi terakhir storyline dimana pemain harus mengumpulkan 10 kayu dan menjawab soal-soal (dapat dilihat pada Gambar 13). Map ini juga menampilkan informasi-infromasi tentang habitat dan kelangkaan dari hewan-hewan khas dari Kalimantan yaitu Ikan Pesut, Orang Utan, dan Burung Enggang.

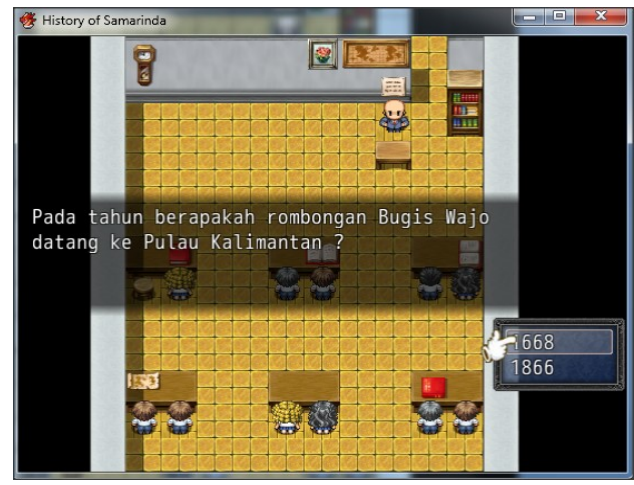

Gambar 13. Tampilan Misi Menjawab Soal 
ISSN : 2085-3688; e-ISSN : 2460-0997

Game Sejarah Terbentuknya Kota Samarinda Menggunakan Role Playing Game (RPG) Maker VX Ace

\section{H. Pengujian}

Pengujian pada game dibagi dua yaitu pengujian Black Box dan Pengujian dari sisi pemain. Pada Tabel 2 ditunjukkan hasil pengujian Black Box.

Tabel. 2 Pengujian Black Box

\begin{tabular}{|c|c|c|c|}
\hline $\begin{array}{c}\text { Aktivitas } \\
\text { Pengujian }\end{array}$ & $\begin{array}{c}\text { Target } \\
\text { Pengujian }\end{array}$ & $\begin{array}{c}\text { Hasil } \\
\text { Pengujian }\end{array}$ & Kesimpulan \\
\hline $\begin{array}{l}\text { Klik 'mulai } \\
\text { game' }\end{array}$ & $\begin{array}{c}\text { Untuk } \\
\text { memulai } \\
\text { permainan }\end{array}$ & $\begin{array}{c}\text { Permainan } \\
\text { dapat } \\
\text { dimulai }\end{array}$ & Diterima \\
\hline Klik 'keluar' & $\begin{array}{c}\text { Untuk } \\
\text { menutup } \\
\text { permainan }\end{array}$ & $\begin{array}{c}\text { Permainan } \\
\text { dapat } \\
\text { berakhir }\end{array}$ & Diterima \\
\hline $\begin{array}{c}\text { Klik kursor } \\
\text { kekiri }\end{array}$ & $\begin{array}{c}\text { Arah NPC ke } \\
\text { kiri }\end{array}$ & $\begin{array}{c}\text { NPC } \\
\text { bergerak ke } \\
\text { kiri }\end{array}$ & Diterima \\
\hline $\begin{array}{c}\text { Klik kursor } \\
\text { ke kanan }\end{array}$ & $\begin{array}{c}\text { Arah NPC ke } \\
\text { kanan }\end{array}$ & $\begin{array}{c}\text { NPC } \\
\text { bergerak ke } \\
\text { kanan }\end{array}$ & Diterima \\
\hline $\begin{array}{l}\text { Klik kursor } \\
\text { ke atas }\end{array}$ & $\begin{array}{c}\text { Arah NPC ke } \\
\text { atas }\end{array}$ & $\begin{array}{c}\text { NPC } \\
\text { bergerak ke } \\
\text { atas }\end{array}$ & Diterima \\
\hline $\begin{array}{l}\text { Klik kursor } \\
\text { ke bawah }\end{array}$ & $\begin{array}{c}\text { Arah NPC ke } \\
\text { bawah }\end{array}$ & $\begin{array}{c}\text { NPC } \\
\text { bergerak ke } \\
\text { bawah }\end{array}$ & Diterima \\
\hline $\begin{array}{l}\text { Klik tombol } \\
\text { 'Enter' }\end{array}$ & lanjutkan misi & $\begin{array}{c}\text { Misi } \\
\text { dimulai }\end{array}$ & Diterima \\
\hline
\end{tabular}

Pengujian pemain merupakan pengujian secara objektif. Pengujian ini dilakukan oleh pemain dengan rentang usia 10-12 tahun dengan jumlah 10 anak [9]. Pengujian dilakukan pada bulan Oktober 2015 di kediaman masing-masing. Selain menguji penggunaan aplikasi terhadap pemain, pengujian juga melakukan tes soal yang telah terdapat pada aplikasi dengan jumlah soal 10 mengenai sejarah smarinda yang telah dijabarkan didalam permainan. pemain memainkan game "Sejarah Terbentuknya Kota Samarinda" dan setelah itu melakukan penilaian terhadap game dengan mengisi tabel penilaian yang telah disediakan.

Tabel.3 Pengujian Pemain

\begin{tabular}{ccccc}
\hline No & Nama & $\begin{array}{c}\text { Umur } \\
\text { (tahun) }\end{array}$ & $\begin{array}{c}\text { Rating } \\
\text { Bintang }\end{array}$ & $\begin{array}{c}\text { Jumlah jawaban } \\
\text { Benar dan salah }\end{array}$ \\
\hline 1 & User 1 & 12 & $* * * * *$ & $\begin{array}{c}\text { Benar }=10 \\
\text { salah }=0\end{array}$ \\
& & & & Benar $=6$ \\
2 & User 2 & 10 & $* * * * *$ & Salah $=4$ \\
& & & & Benar $=10$ \\
3 & User 3 & 11 & $* * * * *$ & salah $=0$ \\
4 & User 4 & 8 & $* * * * *$ & Benar $=6$
\end{tabular}

\begin{tabular}{|c|c|c|c|c|}
\hline No & Nama & $\begin{array}{c}\text { Umur } \\
\text { (tahun) }\end{array}$ & $\begin{array}{l}\text { Rating } \\
\text { Bintang }\end{array}$ & $\begin{array}{l}\text { Jumlah jawaban } \\
\text { Benar dan salah }\end{array}$ \\
\hline & & & & salah $=4$ \\
\hline 5 & User 5 & 10 & $* * * * *$ & $\begin{aligned} \text { Benar } & =10 \\
\text { salah } & =0\end{aligned}$ \\
\hline 6 & User 6 & 12 & $* * * * *$ & $\begin{aligned} \text { Benar } & =10 \\
\text { salah } & =0\end{aligned}$ \\
\hline 7 & User 7 & 11 & $* * * * *$ & $\begin{aligned} \text { Benar } & =10 \\
\text { salah } & =0\end{aligned}$ \\
\hline 8 & User 8 & 7 & $* * * * *$ & $\begin{array}{l}\text { Benar }=7 \\
\text { salah }=3\end{array}$ \\
\hline 9 & User 9 & 10 & $* * * * *$ & $\begin{array}{l}\text { Benar }=9 \\
\text { salah }=1\end{array}$ \\
\hline 10 & User 10 & 12 & $* * * * *$ & $\begin{array}{c}\text { Benar }=10 \\
\text { salah }=0\end{array}$ \\
\hline
\end{tabular}

Keterangan:

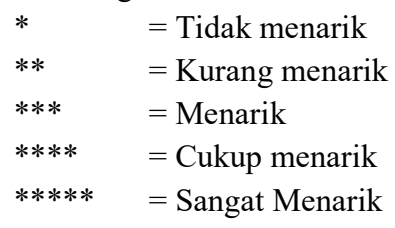

Berdasarkan pengujian pada Tabel 3, bahwa 10 Pemain dari umur 7-12 tahun menilai bahwa permainan ini sangat menarik. sedangkan pengujian berdasarkan soal pada permainan, pemain dengan umur 7- 10 tahun dapat menjawab dengan nilai minimal 6 dan nilai maksimal 10 dan para pemain 1012 tahun mampu menjawab nilai 10 .

Berdasarkan hasil penilaian dari pemain yang memberikan bintang sebagai rating game dan dari banyaknya soal yang dapat dijawab dengan benar pada misi terakhir. dapat disimpulkan bahwa aplikasi game yang dibangun layak untuk dimainkan dan telah memenuhi tujuan yang ingin dicapai yakni menyediakan game menarik yang mengangkat cerita sejarah terbentuknya kota Samarinda, dan juga game ini dapat dimainkan untuk anak-anak di bawah usia 10 tahun. Hal ini terlihat dan sesuai dengan tabel penilaian game yang terdapat pada halaman lampiran.

\section{PENUTUP}

\section{A. Kesimpulan}

Berdasarkan hasil implementasi dan pengujian game "Sejarah Terbentuknya Kota Samarinda", dapat ditarik kesimpulan yaitu Game Sejarah Terbentuknya Kota Samarinda ini dapat dijadikan sebagai alternatif media pembelajaran yang menarik, interaktif dan pemain friendly khususnya untuk pengguna 10-12 tahun. Berdasarkan pengujian game dari 10 pemain 
dengan umur 7-12 tahun menunjukkan bahwa game ini dinilai sangat menarik. Pengujian berdasarkan soal pada permainan menunjukkan bahwa pemain dengan umur 7-10 tahun dapat menjawab dengan nilai minimal 6 dan nilai maksimal 10 dan para pemain 10 12 tahun mampu menjawab dengan nilai 10 . Tentunya dengan media pembelajaran seperti ini penggguna dapat mengingat dan mengetahui sejarah terbentuknya kota Samarinda dengan mudah.

\section{B. Saran}

Adapun saran untuk pengembangan game Sejarah Kota Samarinda adalah sebagai berikut :

1. Pengembangan kepada desain grafis dan musik game yang lebih baik dan lebih menunjukkan suasana Indonesia pada zaman sejarah.

2. Membuat karakter pemain memiliki fitur yang lebih kompleks (dapat menggunakan skill dan perlengkapan) atau dengan menambahkan elemen-elemen game RPG lainnya seperti battle system dan menu system yang lebih menarik.

3. Penambahan fitur timer pada game agar pemain menjadi lebih tertantang dalam bermain game.

4. Pengacakan soal pertanyaan dan pemberian skor di akhir misi agar ending game menjadi lebih menarik.

\section{DAFTAR PUSTAKA}

[1] Suherman, Pepen dan Amir Fatah Sofyan, "Perancangan Game untuk Anak-anak (Petualangan Pepen) Dengan Macromedia Flash," Jurusan teknik Informatika. STMIK Amikom Yogyakarta.Yogyakarta, 2010.

[2] Jasson, "Role Playing Game (RPG) Maker," CV ANDY OFFSET, Yogyakarta, 2009.

[3] Haviluddin, "Memahami Penggunaan UML (Unified Modelling Language)," Jurnal Informatika
Universitas Mulawarman, volume 6, pp 1-15, Universitas Mulawaran, 2011.

[4] Maula, Amiruddin, Syahbandi, dan Achmad Maulana, "Cerita Rakyat Dari Kalimantan Timur", PT Gramedia Widiasarana Indonesia, Jakarta.

[5] Ashari M.R.A, "Game RPG Lorong Waktu-Pangeran Diponegor”, Fakultas Teknik dan Ilmu Komputer, Universitas Komputer Indonesia, Bandung, 2013.

[6] Wibowo dan Aris Setyo,"Pembuatan Game RPG (Pitung : Batavia's Champion) Menggunakan RPG Maker VX," Sekolah Tinggi Manajemen Informatika dan Komputer AMIKOM Yogyakarta, Yogyakarta, 2013.

[7] Junaidi, A.R, "Pemrograman Game RPG Maker VX Ace", Sekolah Tinggi Manajemen Informatika dan Komputer AMIKOM Yogyakarta, Yogyakarta, 2015.

[8] Wulandari, A.D, “Game Edukatif Sejarah Komputer Menggunakan Role Playing Game (RPG) Maker XP Sebagai Media Pembelajaran Di SMP Negeri 2 Kalibawang," Universitas Negeri Yogyakarta, Yogyakarta, 2012.

[9] Wahyu, C.S, “Membangun Game Mini Car Action 2d : Mobilkom", Universitas Mulawarman, Samarinda, 2015. 